\title{
Short Term Complications of Acute Myocardial Infarction in a Tertiary Hospital
}

\author{
Md Nazrul Islam*1, Sabikun Nahar Chowdhury², Md Sajjadur Rahman³, Sk Moazzem Hossain ${ }^{4}$
}

\section{Abstract}

Introduction: Acute myocardial infarction is very common in Bangladesh. It is one of the most common causes of mortality worldwide. The clinical course is associated with various complications. Materials and Methods: To assess the short-term outcome of acute coronary syndrome we select 100 patients. The study was conducted at the Medicine wards of Khulna Medical College Hospital, Khulna from February'2019 to August'2019. We observed the clinical presentations, ECG findings, echocardiographic findings, short term complications and outcome. Results: We found that most of the patients $(61 \%)$ were within 45-64 years of age. Chest pain was the most common (85\%) presentation. NSTEMI is more common than STEMI. 53\% patients developed complications. Acute LVF is the most common (23\%) complication. AV block is the most common arrythmia (10\%). We found overall mortality 38\%. Conclusion: Early detection of complications is essential for reduction of morbidity and mortality. This study will help to evaluate short-term complications and to give appropriate management.

Keywords: Infarction, Complications, NSTEMI, STEMI.

Number of Tables: 05; Number of References: 20; Number of Correspondence: 05.

*1. Corresponding Author:

\section{Dr. Md Nazrul Islam}

Assistant Professor, Department of Medicine

Khulna Medical College, Khulna.

Email: drmdnazrul@gmail.com

Mob: 01725497947

2. Dr. Sabikun Nahar Chowdhury

Junior Consultant, Department of Clinical Pathology

Khulna Medical College Hospital, Khulna.

\section{Dr. Md Sajjadur Rahman}

Assistant Professor, Department of Cardiology

Colonel Malek Medical College, Manikganj.

4. Dr. Sk Moazzem Hossain

Assistant Professor, Department of Medicine

Khulna Medical College, Khulna.

\section{Introduction:}

Coronary artery diseases (CAD) is a common cause of mortality worldwide ${ }^{1}$ and within few years it will be first in the leading cause of disability ${ }^{2}$. Acute Myocardial Infarction (AMI) is the most common form of CAD. When there is rupture of an atherosclerotic plaque or there is erosion with superimposed thrombosis then acute occlusion of coronary artery occurs followed by myocardial infarction. Though AMI is very common in Bangladesh but advanced treatment of AMI (eg. thrombolytic therapies and $\mathrm{PCI}$ ) is not available in every hospital, even in all tertiary level hospitals. As a result, various complications develop in these patients and many patients die. Numerous studies done in our country as well as in abroad shows that various complications may arise after an acute MI such as left ventricular failure, carcinogenic shock, heart block, arrhythmia, cardiac rupture and pericarditis ${ }^{3-7}$. This study was done to see the various complications and outcome of the patients of AMI admitted in a tertiary level hospital in Bangladesh.

\section{Materials and Methods:}

It is an Observational study. The study was conducted at the Medicine wards of Khulna Medical College Hospital, Khulna from February'2019 to August'2019. Patients with Acute Myocardial Infarction admitted in the Medicine wards of Khulna Medical College Hospital were taken.

Sampling method: Purposive sampling.

Inclusion criteria:

- Patients with Acute Myocardial infarction

- Age $>18$ years

- Both male and female

- Voluntarily given consent.

Exclusion criteria:

- Not willing to give informed consent

- Patients with AMI having the following associations:

- Rheumatic and congenital heart diseases

- Chronic liver disease

- Chronic kidney disease

- Malignancy

Informed written consent was taken from the patient. All patients were interviewed by using standard questionnaire containing socio-demographic and relevant information about the study topic. General medical condition of the patients was evaluated through complete history, physical examination and help of investigations. Standard treatment of acute MI was given to all patients and they were followed up till discharge. After collection, data editing and clearing was done manually and prepared for data entry and analysis by using SPSS. 


\section{Results:}

Table I shows age distribution of patients with acute myocardial infarction. Out of 100 patients 29(29\%) were in the age group of 55-64 years and $32(32 \%)$ were in the age group of $45-54$ years. The mean age for AMI is $54.2 \pm 10.75$ years.

Table-I: Age distribution.

\begin{tabular}{lll}
\hline Age group & No (\%) & Mean \pm SD \\
\hline $25-34$ & $4(4)$ & \\
$35-44$ & $15(15)$ & \\
$45-54$ & $32(32)$ & $53 \pm 10.74$ \\
$55-64$ & $29(29)$ & \\
65 and above & $20(20)$ &
\end{tabular}

Table II shows clinical presentation in AMI patients. Chest pain was the most common ( $85 \%$ ) symptom reported. The second and third common symptoms were dyspnea (52\%) and sweating (43\%) respectively. Among other symptoms, anxiety was also found in significant number of patients.

\section{Table-II: Clinical Presentation.}

\begin{tabular}{llc}
\hline Manifestations & No & Percentage \\
\hline Chest pain & 85 & $85 \%$ \\
Dyspnea & 52 & $52 \%$ \\
Sweating & 43 & $43 \%$ \\
Nausea vomiting & 38 & $38 \%$ \\
Anxiety & 27 & $27 \%$ \\
Epigastric pain & 12 & $12 \%$ \\
\hline
\end{tabular}

On the basis of ECG findings MI was divided into STEMI \& NSTEMI. NSTEMI (55\%) was more common than STEMI (45\%).

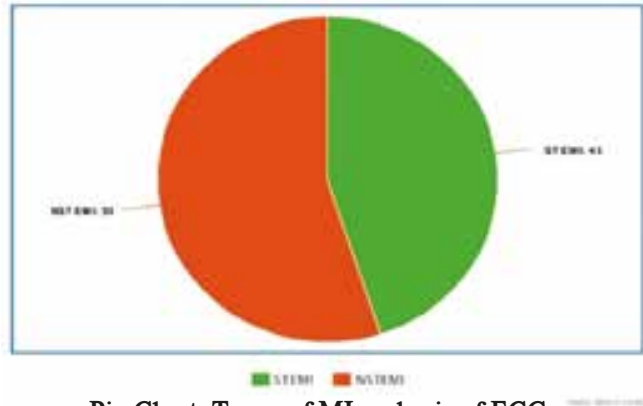

Pie Chart: Types of MI on basis of ECG

Cardiac function was assessed by echocardiography. Systolic dysfunction was found in $33 \%$ cases, diastolic dysfunction in $15 \%$ cases and both systolic and diastolic dysfunction in $30 \%$ cases

Table-III: Echocardiographic findings.

\begin{tabular}{llc}
\hline Echocardiographic findings & No & Percentage \\
\hline Systolic dysfunction & 33 & $33 \%$ \\
Diastolic dysfunction & 15 & $15 \%$ \\
Both systolic and diastolic dysfunction & 30 & $30 \%$ \\
Normal & 22 & $22 \%$ \\
\hline
\end{tabular}

In our study 53\% patients developed complications. Acute left ventricular failure was the most common complication 23\%. Among other complications 17\% developed arrythmia and $13 \%$ developed cardiogenic shock. Among the arrythmias atrioventricular block (AV block) was most common $(10 \%)$. Other arrythmias include ventricular tachycardia (4), ventricular fibrillation (3).
Table-IV: Complications.

\begin{tabular}{lcc}
\hline Complications & No & Percentage \\
\hline Acute LVF & 23 & $23 \%$ \\
Arrythmia & 17 & $17 \%$ \\
Cardiogenic shock & 13 & $13 \%$ \\
Post MI angina & 09 & $09 \%$ \\
Thrombo-embolic phenomenon/ stroke & 02 & $02 \%$ \\
\hline
\end{tabular}

Table-V: Types of arrythmia.

\begin{tabular}{llc}
\hline Types of arrhythmia & No & Percentage \\
\hline Atrioventricular (AV) block & 10 & $10 \%$ \\
Ventricular tachycardia (VT) & 04 & $04 \%$ \\
Ventricular fibrillation (VF) & 03 & $03 \%$ \\
\hline
\end{tabular}

Mortality is $38 \%$.

\section{Discussion:}

This observational study was carried out on 100 cases of Acute Myocardial Infarction (AMI) admitted in the medicine wards of Khulna medical college hospital. Demography, clinical presentations, investigations and outcome were observed.

This study found that, most of the patients were in the age group of $45-54$ years $(32 \%)$. This finding is similar to a study by Islam $\mathrm{M}$ et $\mathrm{al}^{8}$ in 2017 in Bangladesh and in other studies $^{9-10}$.

Chest pain was the most common symptom reported. The second and third most common symptoms were dyspnea and sweating respectively. Among other symptoms, anxiety was also found in significant number of patients. These findings correspond to several other studies ${ }^{11-12}$.

ECG findings revealed that NSTEMI was more common $(55 \%)$ than STEMI (45\%). Similar finding was found in a study by Kjell Nikus et $\mathrm{a}^{13}$. Several studies reveals STEMI more common than NSTEMI ${ }^{14-15}$.

Echocardiographic assessment of cardiac function shows Systolic dysfunction (33\%) both systolic and diastolic dysfunction (30\%) diastolic dysfunction (15\%). These findings are similar to findings in other studies ${ }^{16-17}$.

Acute Left ventricular failure was the most common complications $(23 \%)$, followed by arrythmia (17\%) and cardiogenic shock (13\%). Study also found that AV block was the most common arrythmia $(10 \%)$ followed by VT (4\%) and VF (3\%). These complications correspond with other several studies ${ }^{18-19}$.

In our study we found that mortality rate was 34\%. This result is very similar to a study by Harvey D White ${ }^{20}$.

\section{Conclusion:}

In Bangladesh advanced treatment of AMI (different thrombolytic therapies and PCI) is not available in every health care facility, even in all tertiary care hospitals. So due to delay in diagnosis and lack of availability of appropriate treatment various complications may develop and patients may die. Early detection of complications can reduce morbidity and mortality. Thus, this study may help physicians to be aware of short-term complications and taking essential management. 
Conflict of Interest: None.

\section{Acknowledgement:}

I acknowledge the authors in my references and also my intern doctors helping me in data collection and data analysis.

\section{References:}

1. Islam AK, Majumder AA, Paul T. Coronary Artery Disease in Bangladesh: A Review. Bangladesh Heart J. 2016; 31: 80-99.

https://doi.org/10.1016/j.ihj.2013.06.004

2. Ahmed J, Rathi N, Alam MT, Baloch Z, Munaf A, Maheshwari B, et al. Acute Myocardial Infarction; a comparative study to assess the angiographic changes in diabetic and non-diabetic patients. Professional Med J. 2015; 22: 996-1000.

3. Biswas T, Islam A, Rawal LB, Islam SM. Increasing prevalence of diabetes in Bangladesh: a scoping review. Public Health. 2016; 138: 4-11.

ttps://doi.org/10.1016/j.puhe.2016.03.025

4. American Heart Association / American Stroke Association statistical data on highlights of acute coronary syndrome. $2005 ; 2$ : 31-9.

https://doi.org/.ORG/10.1161

5. Sharma R, Bhairappa S, Prasad SR, Manjunath CN. Clinical characteristics, angiographic profile and in-hospital mortality in acute coronary syndrome patients in south indian population. Heart India. 2014; 2: 65-9.

https://doi.org/10.4103/2321-449X.140228

6. Bajzer CT. Acute myocardial infarction. In: Medicine index. Cleveland Clinic Foundation. 2002; 222-6.

7. Dirkali A, Van Der Ploeg T, Nangrahary M, Cornel JH, Umans VA. The impact of admission plasma glucose on long term mortality after STEMI and NSTEMI myocardial infarction. Int J Cardiol. 2007; 121: 215-7.

https://doi.org/10.5935/abc/20140130

8. Islam M, Bhattacharjee B, Chowdhury MA, Siddique A, \& Karim AM. Outcome of Acute Myocardial Infarction Patients Admitted in a Tertiary Care Hospital; Medicine Today. 2016; 28: 6-9.

\section{https://doi.org/10.3329/MEDTODAY.V28I1.30960}

9. Schoenenberger AW, Radovanovic D, Stauffer JC, Windecker, Urban P, Niedermaier G, et al. Acute coronary syndromes in young patients: presentation, treatment and outcome. Int J Cardiol. 2011; 148: 300-4.

https://doi.org/10.1016/j.ijcard.2009.11.009

10. Pellaton C, Monney P, Ludman AJ, Schwitter J, Eeckhout E, Hugli O, et al. Clinical features of myocardial infarction and myocarditis in young adults: a retrospective study. BMJ Open. 2012; 2:e001571.

https://doi.org/ 10.1136/bmjopen-2012-001571
11. Andersson, P.O., Lawesson, S.S., Karlsson, Nilsson S, Thylen I. Characteristics of patients with acute myocardial infarction contacting primary healthcare before hospitalisation: a cross-sectional study. BMC Fam Pract. 2018; 19:167.

https://doi.org/10.1186/s12875-018-0849-8

12. Goel PK, Srivastava SK, Ashfaq F, Gupta PR, Saxena PC, Agarwal R, et al. A study of clinical presentation and delays in management of acute myocardial infarction in community; Indian Heart J. 2012; 64: 295-301.

https://doi.org/ 10.1016/S0019-4832(12)60090-X

13. Nikus K, Birnbaum Y, Eskola M, Sclarovsky S, Zhong Z, Pahlm O. Updated Electrocardiographic Classification of Acute Coronary Syndromes. Curr Cardiol Rev. 2014; 10: 229-236.

https://doi.org/10.2174/1573403X10666140514102754

14. Liu CH, Huang YC. Comparison of STEMI and NSTEMI patients in the emergency department. Journal of Acute Medicine. 2011; 1: 1-4.

https://doi.org/10.1016/J.JACME.2011.08.001

15. Deora S, Kumar T, Ramalingam R, Nanjappa Manjunath C. Demographic and angiographic profile in premature cases of acute coronary syndrome: analysis of 820 young patients from South India. Cardiovasc Diagn Ther. 2016; 6:193-198.

https://doi.org/10.21037/cdt.2016.03.05

16. Flachskampf FA, Schmid M, Rost C, Achenbach S, DeMaria AN, Daniel WG. Cardiac imaging after myocardial infarction; European Heart Journal. 2011; 32:272-283.

https://doi.org/10.1093/eurheartj/ehq446

17. Shivpuje AV, Page S. Echocardiographic assessment of left ventricular function in patients of acute myocardial infarction. International Journal of Advances in Medicine. 2017; 4: 926-931.

http://dx.doi.org/10.18203/2349-3933.ijam20173070.

18. Bajaj A, Sethi A, Rathor P, Suppogu N, Sethi A. Acute Complications of Myocardial Infarction in the Current Era: Diagnosis and Management. J Investig Med. 2015; 63:844-55.

https://doi.org/10.1097/JIM.0000000000000232

19. Marangmei L, Singh SK, Devi KB, Raut SS, Chongtham DS, Singh KB. Profile of cardiac arrhythmia in acute myocardial infarction patients within 48 hours of admission: A hospital-based study at RIMS Imphal. J Med Soc. $2014 ; 28: 175-9$.

https://doi.org/10.4103/0972-4958.148514

20. Chew D, White HD. Myocardial Infarction Mortality Where Do We Go Now? European Cardiovascular Disease. 2007; 3:33-34.

https://doi.org/10.15420/ecr.2007.0.1.33 